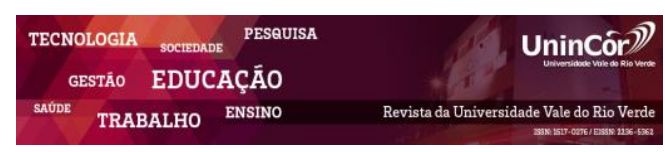

Revista da Universidade Vale do Rio Verde ISSN: 1517-0276 / EISSN: 2236-5362 v. $17 \mid$ n. 1 | Ano 2019

\section{ANÁLISE DE INVESTIMENTO NO SETOR FINANCEIRO DA B3}

\section{RESUMO}

Este trabalho tem por objetivo analisar a viabilidade econômica nos investimentos no setor financeiro da B3. O trabalho concentrou-se em buscar dados como os preços das ações, os dividendos e juros sobre capital próprio de seis das principais empresas desse setor. Por meio dos dados foi possível a visualização comparativa entre os rendimentos das ações analisadas e os indicadores econômico-financeiros do período de 2010 a 2016. Conclui-se que o retorno nominal e retorno real do investimento no setor financeiro da B3 são superiores ao IPCA nas empresas Cielo S.A., Banco Santander S.A. e B3 S.A. sendo que o destaque foi a Cielo S.A contando com retorno nominal de $196,89 \%$ e o retorno real de $106,53 \%$.

Palavras-chave: Viabilidade Econômica; Retorno Acionário; Rentabilidade.

\section{INVESTMENT ANALYSIS IN THE B3 FINANCIAL SECTORE}

\begin{abstract}
The purpose of this work is to analyze the economic viability of investments in the financial sector of B3. The work focused on data such as stock prices, dividends and interest on equity of six of the leading companies in this sector. Through the data, it was possible to compare the yields of the shares analyzed with the economic and financial indicators for the period from 2010 to 2016. It can be concluded that the nominal return and real return on investment in the financial sector of B3 are higher than the IPCA in Cielo SA, Banco Santander SA and B3 SA - the main highlight being Cielo SA with a nominal return of $196.89 \%$ and a real return of $106.53 \%$.
\end{abstract}

Keywords: Economic Viability; Shareholder Return; Profitability.

Recebido em: 18/03/2018 - Aprovado em: 02/04/2019 - Disponibilizado em: 15/07/2019

\section{INTRODUÇÃO}

Retorno é um termo conveniente aos investidores para designar um desempenho financeiro de certo investimento, e taxa de retorno

é a medida da performance do investimento mais usada. Assim, Brigham e Ehrhardt (2012) dizem que embora a expressão dos retornos em unidade 
monetária seja fácil, surgem dois problemas: (1) para fazer um julgamento correto a respeito do retorno, você precisa conhece a escala (tamanho) do investimento; (2) você também precisa conhecer o tempo oportuno de ocorrência desse retorno.

A julgar que os investidores gostam de retornos e não gostam de risco, sendo que haverá investimento em ativos mais arriscados somente se esperarem receber retornos mais altos, é estabelecida uma relação entre risco e retorno. Nas palavras de Assaf Neto (2011) "risco pode ser entendido pela capacidade de mensurar o estado de incerteza de uma decisão mediante o conhecimento das probabilidades associadas á ocorrência de determinados resultados ou valores".

É notória a associação direta entre a potencial ocorrência de certo resultado em relação ao valor médio esperado, não deixando de mencionar que de um modo geral, os risco se dividem em duas categorias: risco não diversificável - ou risco sistemático - que Leite (1994) menciona como o risco que tem origem nas flutuações a que está sujeito o sistema econômico como um todo; e o risco diversificável - ou risco de mercado - são os peculiares para certa empresa, grupo ou setor econômico, pais ou região, e portanto podem ser parcialmente ou totalmente diluído pela diversificação da carteira (coleção de investimento em títulos).

Nesse momento se faz necessário tomar uma posição diante dos investimentos segundo seus riscos e retorno, no entanto essa avaliação é subjetiva e dependente do perfil de decisões do investidor, há diversas formas de decodificar essa relação risco/retorno para maximizar a utilidade (i.e. grau de satisfação) do investidor.

A estratégia para redução de risco habitualmente empregada é a diversificação apresentada através do estudo mais tarde denominado Teoria Moderna Das Carteiras de Markowitz em 1952 que pela primeira vez desenvolvia o tema, em um embasamento teórico matemático em relação à redução de risco resultante da diversificação (COSTA; ASSUNÇÃO, 2005).

O mercado de capitais pode atender a essa necessidade, esse mercado é o sistema que faz a distribuição de valores mobiliários trazendo liquidez para os títulos emitidos pelas empresas a fim de favorecer os recursos de capitalização. Destarte, a única bolsa de valores brasileira é a B3, nome que faz alusão a Brasil, Bolsa e Balcão, é uma entidade autorregulada e supervisionada pela Comissão de Valores Mobiliários (B3, 2017).

Dentre os diferentes tipos de empreendimentos empresariais, as sociedades por ações são as mais importantes (ROSS, 2015). E diante da necessidade de buscar um retorno maior, os investidores são atraídos pelo mercado financeiro e por consequência um maior risco nas operações. Neste contexto, o presente trabalho tem por objetivo analisar a viabilidade econômica nos investimentos no setor financeiro da B3.

Os balanços das operações do mês de abril de 2017, divulgados pela B3 apontam um total de 579.140 investidores pessoa física, representando um volume financeiro de negociado de R\$ 141,10 bilhões (B3, 2017). Percebe-se, na última década a mudança de atitude dos 
indivíduos que passaram a investir no mercado de capitais ao invés de guardar dinheiro na então carteira de poupança, mudança tal que foram incentivadas pelos próprios agentes do mercado financeiro (GRUN, 2010).

Porém, muitos desses novos investidores não possuem embasamento e tão pouca estrutura emocional adequada, suficiente e preparada para lidar com atuações no mercado de ações (BONALDI, 2010). Já Assaf Neto (2007) afirma que as empresas que operam na bolsa podem captar recursos para investimentos em projetos e expansão de negócios, sendo que as bolsas de valores desempenham função muito importante na economia de um país, pois elas contribuem para o crescimento da riqueza nacional através da participação da poupança de cada agente econômico, contribuindo assim para a geração de empregos, entre outros fatores para o crescimento do Produto Interno Bruto (PIB), enfim, para o aumento da riqueza real de uma nação.

Por sua vez, Paula (2010) estudou o mercado acionário brasileiro, analisando o cenário do período entre 2007 e 2008, concluindo que dentre os principais ativos financeiros disponíveis no mercado, os Fundos de Investimentos em ações foram a melhor alternativa de investimento.

\section{REVISÃO TEÓRICA}

Para compreender o retorno acionário, a B3 (2017) define ação como: "títulos de propriedade que conferem a seus detentores (investidores) a participação na sociedade da empresa". Assim, as ações possuem duas classes, como é previsto na Lei ${ }^{\circ}$ 6404/76 que regem as
Sociedades por ações, essa relata que as ações se distinguem conforme a natureza dos direitos ou vantagens que concedem aos seus titulares, sendo elas ações ordinárias, preferenciais e de fruição.

A principal diferença entre as ações ordinárias e preferenciais é que as ordinárias dão ao seu possuidor privilégio de voto nas assembleias de acionistas e as preferenciais concedem o recebimento de dividendos em valor maior ao das ações ordinárias, no mínimo de $10 \%$ e também a preferência no recebimento de reembolso do capital. E as ações de fruição não configuram determinantemente o capital social, poremos títulos que representam ações amortizadas, i.e., possui um dono, ficando a cargo de outra pessoa usufrui dos direitos (BRASIL, 1976).

Entre os proventos que os acionistas recebem, destaca-se os pagos em dinheiro, chamados dividendos e os juros sobre capital próprio, os dividendos representam uma parcela do lucro liquido da empresa. Os juros sobre capital próprio são contabilizados como despesa para empresa (COMISSÃO DE VALORES MOBILIÁRIOS, 2014).

O estudo de Ross, Westerfield e Jaffe (2009) diz que o retorno de qualquer investimento em ações, assim como em qualquer outra aplicação, é composto por dois elementos (1) rendimentos e (2) o ganho ou perda de capital. Sendo assim, o retorno total seria a soma desse rendimento (no caso de ações é o dividendo e juros sobre capital próprio) mais a variação do preço da ação dividida pelo preço inicial. 
Outra variável a se considerar é o tempo, Gitman (2010) ressalta que o retorno é o ganho ou prejuízo total que se obtém com um investimento ao longo de certo período de tempo. Investimento de curto prazo compreende um período de ate dois anos, o médio prazo é caracterizado pelo resgate até o quinto ano, e o longo prazo o investimento é aquele que vai além dos cinco anos.

Tratando de decisões de investimento, um fato importante da economia é a inflação e deve ser considerado. Como explicado por Ross, Westerfield e Jaffe (2009) a inflação possui um efeito maior nas taxas de juros, pois reduz o poder de comprar e a taxa real de retorno sobre investimentos. A utilização do retorno nominal poderá comprometer decisões de investimento.

Terra (2006) aborda que o retorno acionário e inflação esperada estão negativamente relacionados. Diante disso é apontada a taxa nominal de retorno e a taxa real de retorno, e a principal distinção entre essas taxas é que a taxa nominal é aquela divulgadas pelas instituições financeiras, e a taxa real é o resultado da diferença entre o retorno nominal e a inflação do período.

Por sua vez, quanto à relação entre o retorno e o risco, os autores são categóricos em relatar que os investidores realmente possuem a aversão ao risco. Brigham (2012) discorre sobre essa relação começando pela definição da palavra risco situada no dicionário Webster's como "perigo; ameaça; exposição a perdas ou danos", logo isso faz referência às chances de algo desfavorável ocorra.
Com a definição de risco esclarecida e entendo que no contexto financeiro, Gitman (2010) afirma que o risco é usado de forma intercambiável com incerteza em referência à variabilidade dos retornos associados a um determinado ativo. Todavia, o risco não é um só, possui varias facetas, e.g., o risco de taxa de juros, risco de liquidez, risco de mercado que são os comumente enfrentados por acionistas por serem os mais importantes para essa classe.

Dentre todos os riscos existentes, esses podem se englobar em uma das duas classificações o risco não sistemático que é a parte do risco de um ativo que é atribuível a causas aleatórias e específicas a certo âmbito (também chamado de risco diversificável, pois pode ser eliminado a partir da diversificação) e o risco sistemático, também chamado de risco de mercado, pois é uma porção relevante do risco de um ativo, atribuível a fatores de mercado que afetam todas as empresas (ou risco não diversificável, não é possível eliminar através da diversificação) (GITMAN, 2010).

Sabendo que há uma maneira de reduzir o risco não sistemático por meio da diversificação, o investidor passa a se preocupar em como mensurar o risco de uma carteira, e como medir o risco de uma ação individual nessa situação. Brigham e Ehrhardt (2014) nos explicam que uma ferramenta importante para analisar a relação entre risco e taxas de retorno é o Capital Asset Pricing Model (CAPM) apresentados por Harry Markowitz e Willian F. Sharpe, uma teoria que conta como premissa básica: O risco relevante de uma ação individual é sua contribuição ao risco 
de uma carteira bem diversificada. Pode se concluir que certa ação é arriscadíssima isoladamente, mas seu risco é reduzido em torno da metade pela diversificação e o risco relevante dessa ação é o que ele contribui para o risco da carteira, sendo muito menor que o seu risco unitário.

Porém o risco inalterado na diversificação é o risco não sistemático, que é relativo ao mercado, e uma carteira bem diversificada com certeza conta com todas as ações, uma carteira de mercado. Lucena e Motta (2004) pretextam que o coeficiente beta é o meio definido pelo CAPM para indicar o risco relevante de uma ação individual.

Nas observações feitas por Santos e Fonte (2013) no discorrer das características do Beta do CAPM é disposto que, por exemplo, quando o resultado de beta é zero, significa que esse ativo é livre de risco e seu retorno conforme. Sendo o beta menor que 1 , é menos arriscado porém com retorno abaixo do mercado. Caso apresente resultado igual a 1 , o risco é médio e o retorno é igual ao mercado. E no qual o resultado é acima de 1 , o retorno é acima do mercado, no entanto é mais arriscado. Vale destacar ainda Arbitrage Pricing Theory (APT) desenvolvida por Ross em (1976) que segue uma estrutura de fatores, por exemplo, juros e Produto Interno Bruto (PIB), que alteram o retorno acionário (ROSS; WETERFIELD, JAFFE, 2009), sendo essa capacidade de lidar com diversos fatores a diferença central do CAPM.

E ainda sobre APT, nos estudo de Costa e Silva (2009) que articularam sobre o APT no mercado bancário brasileiro discorreram a cerca do fato de mesmo que CAPM consideram a correlação positivas risco/retorno, esse não indica quais fatores levam a essa relação, porem no APT o risco e, portanto o retorno não é apenas percebido como a covariância padronizada ou o beta da ação em relação à carteira de mercado, mas passa por uma serie de informações (fatores).

Por sua vez, Lencione (2005) estudou a comparabilidade entre os modelos de precificação CAPM e APT, e conclui que baseado na Suposição de Arbitragem, o APT oferece um modelo mais flexível, na medida em que há um amplo conjunto de fatores possíveis para explicar a eficiência de subpopulações, sem a necessidade do retorno da carteira (teórica) de mercado, mas utilizando-se do retorno de qualquer "portfólio" diversificado.

\section{METODOLOGIA}

Esta pesquisa acadêmica, quanto a sua objetividade, se classifica como descritiva, pois busca no primeiro instante analisar a viabilidade econômica financeira de determinado investimento. Valendo se quando a sua abordagem do problema da tipologia da pesquisa denominada quantitativa, que segundo Beuren (2003) é caracterizada por instrumentos estatísticos na coleta e no tratamento de dados, e ainda que a busca do conhecimento da realidade dos fatos, não é tão profunda quando a preocupação com o comportamento geral dos acontecimentos.

$\mathrm{O}$ estudo procura analisar o desempenho das ações das 6 (seis) maiores empresas do setor financeiro da B3: (1) CIELO S.A.; (2) Itaú Unibanco Holding S.A.; (3) Banco do Brasil 
S.A.; (4) Banco Santander S.A.; (5) Banco Bradesco S.A.; (6) B3 S.A.. Essas sociedades são destaques no setor financeiro com 37 empresas listadas na B3, as ações e seus proventos (dividendos, juros sobre capital próprio, subscrição...) refletem com notoriedade como cada empresa se situa no mercado, ou seja, se os papéis (ou títulos) da certa empresa estão sendo bem cotados ou não. E o setor financeiro é o setor com maior movimentação financeira e um dos que mais pagou dividendos entre os anos de 1999 e 2013, segundo um levantamento da consultoria Economática.

O período escolhido para análise se inicia em 01/01/2010 com resgate em 31/12/2016, por se tratar de um período de maior desempenho da bolsa de valores brasileira, com recordes de movimentação e volume médio negociado em reais memoráveis em 2013 e 2016 (ECONOMATICA, 2016). Trata-se de um investimento de longo prazo, pois está acima de 5 anos de aplicação, como tal, permite que exista planejamento e organização para o período maior, o que melhora a possibilidades de diversificação, consequentemente diminuindo os risco, além disso, as carteiras de longo prazo possibilitam a incidência de menores taxas de impostos de renda e taxas de retornos mais elevadas (EID JUNIOR, 2017).

Os dados serão coletados no site da B3 e se fizer necessário buscar no site das próprias empresas, informações como o valor negociado de ações, dividendos e juros sobre capital próprio pago aos acionistas no período já mencionado de análise da pesquisa, além de outros índices sendo o de inflação, IPCA (Índice de Preços ao
Consumidor Amplo) e o IGPM (Índice Geral de Preços do Mercado) fundamental para o cálculo do real retorno, bem como taxa de juros, a SELIC (Sistema Especial de Liquidação e Custódia) e para medir a eficiência dos resultados a mérito comparativo da rentabilidade do CDI (Certificado de Depósito Interbancário) e da carteira de poupanças.

Para avaliação dos retornos reais será utilizado, inicialmente, o somatório do preço das ações no final de 2016 e os proventos (dividendos e juros sobre capital próprio) divididos pelo preço da ação no início de 2013, calculando se empresas por empresas das selecionadas para amostra, e também o seu respectivo setor, para efeito comparativo na relação empresa setor e com as demais aplicações concernentes. Por fim, o valor encontrado anteriormente dividido pelo valor inicial acrescido da inflação no período de análise. Resultando no capital investido mais o retorno real do período.

\section{ANÁLISE E DISCUSSÃO DOS DADOS}

A análise foi realizada em empresas do setor financeiro da B3, limitando-se ao número restrito delas, para efeito de tal e estudo acurada, as tabelas de análise e retorno acionário é composta pelos retornos nominal e real de cada ação, além do preço inicial e final, como também o valor dos dividendos e juros pagos durante o período.

\subsection{CIELO}

Cielo é uma empresa brasileira que atua como responsável pela captura, transmissão e liquidação financeira de transações com cartões 
de crédito e débito, sendo a empresa líder do setor em toda a América Latina, em termos de Volume Financeiro de Transações e é uma das responsáveis pelo credenciamento do comércio brasileiro a sua rede de pagamentos.

Em junho de 2014 a Cielo estava presente em mais de 1,4 milhão de pontos de venda espalhados por 5.500 municípios de todas as regiões do país, cobrindo $99 \%$ do território nacional. Conforme o observado na Tabela 2 a
Cielo S.A. possui o retorno nominal de $196,89 \%$ e o retorno real da casa dos $106,53 \%$, possuindo assim o maior retorno do mercado financeiro adotado nessa pesquisa, superando todos os indicadores econômico-financeiros listados na Tabela 1.

Tabela 1: Analise e Retorno - Cielo S.A.

\begin{tabular}{l|c}
\hline Empresa: CIELO & Código da Ação: CIEL3 \\
\hline PREÇO INICAL EM 04/01/2010 & $\mathrm{R} \$ 13,17$ \\
\hline PREÇO FINAL EM 29/12/2016 & $\mathrm{R} \$ 27,89$ \\
\hline DIVIDENDO/JURO TOTAL & $\mathrm{R} \$ 15,16$ \\
\hline Retorno Nominal & $196,89 \%$ \\
\hline Retorno Real & $106,53 \%$ \\
\hline
\end{tabular}

Fonte: Dados da pesquisa (2017)

\subsection{ITAÚ UNIBANCO}

Itaú Unibanco é o maior banco privado do Brasil, com sede na cidade de São Paulo. O banco foi criado em 4 de novembro de 2008 a partir da fusão entre o Banco Itaú e o Unibanco, duas das maiores instituições financeiras do país, resultando no maior conglomerado financeiro do hemisfério sul e num dos 20 maiores do mundo em valor de mercado.

Presente em 21 países, o banco possui cerca de 5 mil agências no Brasil e no exterior e
26 mil caixas eletrônicos e pontos de atendimento. Em 2016, a carteira de ativos do Itaú atingiu $\mathrm{R}$ \$ 1,43 trilhão - a maior do país. O Itaú nos resultados apresentados segue com o percentual de retorno nominal $0,90 \%$ e retorno real $-32,99 \%$ abaixo dos alçando pelo IPCA do período, entre outros indicadores conforme Tabela 2.

Tabela 2: Analise e Retorno - Itaú Unibanco Holding S.A.

\begin{tabular}{l|r}
\hline Empresa: ITAÚ UNIBANCO & Código da Ação: ITUB4 \\
\hline PREÇO INICAL EM 04/01/2010 & $\mathrm{R} \$ 40,12$ \\
\hline PREÇO FINAL EM 26/12/2016 & $\mathrm{R} \$ 33,85$ \\
\hline DIVIDENDO/JURO TOTAL & $\mathrm{R} \$ 8,70$ \\
\hline
\end{tabular}




\begin{tabular}{l|r}
\hline Retorno Nominal & $0,90 \%$ \\
\hline Retorno Real & $-32,99 \%$ \\
\hline
\end{tabular}

Fonte: Dados da pesquisa (2017).

\subsection{BANCO DO BRASIL}

Banco do Brasil S.A. é uma instituição financeira brasileira, constituída na forma de sociedade de economia mista, com participação da União em 54\% das ações. Sua missão, segundo sua filosofia corporativa, é "Ser um banco de mercado, competitivo e rentável, atuando com espírito público em cada uma de suas ações junto à sociedade".

Segundo dados do próprio banco, a empresa possui 15133 pontos de atendimento distri- buídos pelo país, entre agências e postos, sendo que $95 \%$ de suas agências possuem salas de autoatendimento (são mais de 40 mil terminais), que funcionam além do expediente bancário. Possui ainda opções de acesso via internet, telefone e telefone celular. Está presente em mais de 21 países além do Brasil. Nos cálculos relacionados ao Banco do Brasil, apesar de um retorno nominal positivo $31,77 \%$ o retorno real $-8,50 \%$ apresentou um baixo desempenho em comparação com os indicadores econômico-financeiros da Tabela 3.

Tabela 3: Analise e Retorno - Banco do Brasil S.A.

\begin{tabular}{|c|c|}
\hline Empresa: $\quad$ B. BRASIL & Código da Ação: $\quad$ BBAS3.SA \\
\hline PREÇO INICAL EM 04/01/2010 & $\mathrm{R} \$ 29,90$ \\
\hline PREÇO FINAL EM 29/12/2016 & $\mathrm{R} \$ 28,09$ \\
\hline DIVIDENDO/JURO TOTAL & $\mathrm{R} \$ 15,21$ \\
\hline Retorno Nominal & $31,77 \%$ \\
\hline Retorno Real & $-8,50 \%$ \\
\hline
\end{tabular}

Fonte: Dados da pesquisa (2017)

\subsection{SANTANDER}

O Banco Santander (Brasil) S.A.é a subsidiária do banco espanhol Banco Santander no Brasil. Sediada em São Paulo, a operação brasileira entrou em atividade desde 1982 e é parte integrante do Grupo Santander, de origem espanhola, que é o principal conglomerado financeiro da Zona do Euro. É o terceiro maior banco privado do Sistema financeiro do Brasil, com ativos totais de $\mathrm{R} \$ 605,3$ bilhões e 31 milhões de clientes no final de 2014.
Santander Brasil tem ações ordinárias, preferenciais e units listadas na Bolsa de Valores B3, além de negociar American Depositary Receipt (ADR's) na Bolsa de Valores de Nova York. Com o percentual de retorno nominal de $52,13 \%$ e retorno real $1,42 \%$ positivo Banco Santander possui o terceiro lugar de melhor desempenho das empresas escolhidas do setor financeiro para a amostra desse trabalho de acordo com a Tabela 4. 
Tabela 4: Analise e Retorno - Banco Santander S.A.

\begin{tabular}{|c|c|c|}
\hline Empresa: $\quad$ SANTANDER & Código da Ação: & SANB11 \\
\hline PREÇO INICAL EM 04/01/2010 & & $\mathrm{R} \$ 23,75$ \\
\hline PREÇO FINAL EM 26/12/2016 & & $\mathrm{R} \$ 29,53$ \\
\hline DIVIDENDO/JURO TOTAL & & $\mathrm{R} \$ 8,59$ \\
\hline Retorno Nominal & & $52,13 \%$ \\
\hline Retorno Real & & $1,42 \%$ \\
\hline
\end{tabular}

Fonte: Dados da pesquisa (2017)

\subsection{BRADESCO}

Bradesco é um banco brasileiro, atualmente é considerada a maior e mais valiosa marca da América Latina, consistindo no mais lucrativo banco privado do Brasil dos últimos anos, sendo o segundo maior banco privado do Brasil, cresceu principalmente através de fusões e aquisições.
Com mais de 4.600 agências, o Bradesco é o único banco privado brasileiro a estar presente em todos os municípios do país, com pelo menos uma agência em cada uma das 5.564 cidades do Brasil. Na Tabela 6 estão os valores dos retorno nominal e retorno real do Banco Bradesco, $0,03 \%$ e $-32,42 \%$ respectivamente, porem muito inferior aos índices econômicos da Tabela 5.

Tabela 5: Analise e Retorno - Banco Bradesco S.A.

\begin{tabular}{|c|c|c|}
\hline Empresa: $\quad$ BRADESCO & Código da Ação: & BBDC4 \\
\hline PREÇO INICAL EM 04/01/2010 & & $\mathrm{R} \$ 37,70$ \\
\hline PREÇO FINAL EM 29/12/2016 & & $\mathrm{R} \$ 29,00$ \\
\hline DIVIDENDO/JURO TOTAL & & $\mathrm{R} \$ 11,32$ \\
\hline Retorno Nominal & & $-0,03 \%$ \\
\hline Retorno Real & & $-32,42 \%$ \\
\hline
\end{tabular}

Fonte: Dados da pesquisa (2017)

\subsection{B3}

B3 (Brasil, Bolsa, Balcão) é a bolsa de valores oficial do Brasil. Sediada na cidade de São Paulo, ela surgiu sob o formato atual após a fusão da Bolsa de Valores, Mercadorias e Futu- ros de São Paulo (BM\&FBOVESPA S.A.) com a Central de Custódia e de Liquidação Financeira de Títulos (CETIP S.A.), aprovada pela Comissão de Valores Mobiliários (CVM) e pelo Conselho Administrativo de Defesa Econô- 
mica (CADE) em 22 de março de 2017. A empresa passou a ser a $5^{\circ}$ maior bolsa do mercado de capital do mundo, com valor de mercado de 13 bilhões de dólares.

Em 29 de agosto de 2014 as empresas cotadas na Bovespa bateram o maior recorde da história em valor de mercado, todas as 328 companhias listadas na bolsa brasileira valiam 2,595 trilhões de reais, o número de empresas com pa- péis negociados no pregão chegou a 344 no fim de 2017. A bolsa é uma entidade autor reguladora que opera sob a supervisão da Comissão de Valores Mobiliários (CVM). Com o segundo lugar de melhor desempenho das empresas da amostra dessa pesquisa a B3 conta com um retorno nominal de $55,31 \%$ e o retorno real de $4,18 \%$, superando alguns dos indicadores da Tabela 6.

Tabela 6: Analise e Retorno - B3 S.A. - Brasil, Bolsa, Balcão.

\begin{tabular}{|c|c|c|}
\hline Empresa: $\quad \mathrm{B} 3$ & Código da Ação: & BVMF3 \\
\hline PREÇO INICAL EM 04/01/2010 & & $\mathrm{R} \$ 12,95$ \\
\hline PREÇO FINAL EM 29/12/2016 & & $\mathrm{R} \$ 16,50$ \\
\hline DIVIDENDO/JURO TOTAL & & $\mathrm{R} \$ 4,85$ \\
\hline Retorno Nominal & & $55,31 \%$ \\
\hline Retorno Real & & $4,18 \%$ \\
\hline
\end{tabular}

Fonte: Dados da pesquisa (2017)

\subsection{SÍNTESE DOS INVESTIMENTOS}

A Tabela 7 expõe de forma conjugada e organizada de modo decrescente, do melhor para o menor desempenho, comparando a rentabilidade do setor financeiro com outros fundamentos intrínsecos da análise de investimento.

Tabela 7: Investimento em ações setor financeiro B3 - 2010/2016

\begin{tabular}{|c|c|c|c|c|c|}
\hline \multirow{2}{*}{ EMPRESA } & \multicolumn{2}{|c|}{ PREÇO DA AÇÃO } & \multirow{2}{*}{$\begin{array}{c}\text { DIVIDENDO } \\
+ \text { +JSCP }\end{array}$} & \multicolumn{2}{|c|}{ RETORNO } \\
\hline & INICIAL & FINAL & & NOMINAL & REAL \\
\hline Cielo & $\mathrm{R} \$ 13,17$ & $\mathrm{R} \$ 27,89$ & $\mathrm{R} \$ 15,16$ & $196,89 \%$ & $106,53 \%$ \\
\hline B3 & $\mathrm{R} \$ 12,95$ & $\mathrm{R} \$ 16,50$ & $\mathrm{R} \$ 4,85$ & $55,31 \%$ & $4,18 \%$ \\
\hline Santander & $\mathrm{R} \$ 23,75$ & $\mathrm{R} \$ 29,53$ & $\mathrm{R} \$ 8,59$ & $52,13 \%$ & $1,42 \%$ \\
\hline Banco do Brasil & $\mathrm{R} \$ 29,90$ & $\mathrm{R} \$ 28,09$ & $\mathrm{R} \$ 15,21$ & $31,77 \%$ & $-8,50 \%$ \\
\hline Bradesco & $\mathrm{R} \$ 37,70$ & $\mathrm{R} \$ 29,00$ & $\mathrm{R} \$ 11,32$ & $-0,03 \%$ & $-32,42 \%$ \\
\hline Itaú Unibanco & $\mathrm{R} \$ 40,12$ & $\mathrm{R} \$ 33,85$ & $\mathrm{R} \$ 8,70$ & $0,90 \%$ & $-32,99 \%$ \\
\hline \multicolumn{6}{|l|}{ ÍNDICE } \\
\hline Inflação & & & & $58,25 \%$ & \\
\hline Poupança & & & & $63,35 \%$ & \\
\hline Ibovespa & & & & $-12,17 \%$ & \\
\hline SELIC - TESOURO & & & & $110,53 \%$ & \\
\hline
\end{tabular}




\begin{tabular}{l|l|l|l|l|l}
\hline IPCA Acumulado & & & & $58,23 \%$ & \\
\hline
\end{tabular}

Fonte: Dados da pesquisa (2017)

Sabendo que o objetivo central do investimento é a obtenção de rendimentos para o investidor, julgando sua viabilidade, e ainda, quando existe mais de uma opção, é preciso reconhecer aquela que alcançará a melhor rentabilidade. Das empresas estudadas a que melhor traduz essa rentabilidade é a Cielo S.A. com seu retorno real superando índices de inflação e poupança, além de apresentar o segundo melhor valor de dividendos de $\mathrm{R} \$ 15,16$, que nesse quesito só perdeu para o Banco do Brasil, que pagou dividendos no valor de $\mathrm{R} \$$ 15,21 no período.

A ação do Itaú Unibanco apresentou desempenho mais baixo, com o retorno real negativo de $-32,99 \%$, com dividendos menor do que a metade das empresas pesquisadas, de apenas R\$ 8,70. Portanto, sinteticamente a melhor opção de investimento é a ação da Cielo e a pior foi a ação do Itaú Unibanco.

\section{CONSIDERAÇÕES FINAIS}

A análise da viabilidade econômica do investimento no setor financeiro da B3 foi o objetivo central dessa pesquisa, resultado esse que expõe positivamente a viabilidade de tal investimento, apresentando percentual positivo (quanto ao retorno real) em três das seis empresas estudadas no trabalho, destacando se a Cielo superando todos os indicadores econômicofinanceiros que esse trabalho utilizou para efeito de comparativo, como a SELIC, IPCA, poupança, entre outros.
A pesquisa evidenciou que o retorno nominal de apenas uma empresa foi negativo, a do Banco do Bradesco, porém o Banco do Brasil e o Itaú obtiveram o retorno real negativo, e outras três tiveram posição de destaque referente ao seu retorno real e retorno nominal positivo, sendo na sequencia do maior para o menor a Cielo, B3 e Santader.

Em segundo plano o trabalho pode questionar os resultados distintos de empresas do mesmo setor, destacando a Cielo que alcançou o melhor desempenho de rentabilidade do período pelo fato de ser líder no mercado latino-americano das transações financeiras de cartões de credito e debito, para o Santader seria o apoio de grupos estrangeiros, e a B3 pela consolidação no mercado e o seu porte, considerada uma das maiores bolsa de valores do mundo.

Nesse sentido, grau de êxito econômico de uma empresa em relação ao capital nela aplicado, isto é, o nível de rentabilidade das empresas pesquisadas confirma o que foi questionado pelo estudo, corroborando com melhor desempenho de retorno real das três melhores empresas da pesquisa.

Para novas pesquisas, sugerese verificar os retornos nominal e real de diversos setores da economia para demonstrar a viabilidade dos investimentos no mercado acionário brasileiro. Outra possibilidade seria encontrar os fatores endógenos ou exógenos que justificam a rentabilidade das empresas do setor financeiro. 


\section{REFERÊNCIAS}

ASSAF NETO, Alexandre - Mercado Financeiro. - 10. Ed - São Paulo: Atlas, 2011.

Finanças Corporativas e Valor. 3. ed.

São Paulo: Atlas, 2007

BEUREN, Ilse Maria. Trajetória da construção de um trabalho monográfico em

contabilidade. Como elaborar trabalhos monográficos em contabilidade: teoria e prática, v. 2, 2003.

BOLSA DE VALORES, MERCADORIAS E FUTUROS DE SÃO PAULO (BM\&FBovespa).

Perfil dos Investidores. Disponível em: <http://www.bmfbovespa.com.br/pt_br/servicos/ market-data/consultas/historico-pessoas-fisicas/>. Acesso em: 24 de Março de 2017.

\section{BOLSA DE VALORES, MERCADORIAS E} FUTUROS DE SÃO PAULO (BM\&FBovespa).

Lista de produtos a vista e derivativos, renda variável: Acões.Disponível

em:<http://www.bmfbovespa.com.br/pt_br/produt os/listados-a-vista-e-derivativos/rendavariavel/acoes.htm>. Acesso em: 11 de Junho 2017

BONALDI, E. O pequeno investidor na bolsa brasileira: uma análise da ação e da cognição econômica, São Paulo, 202 f. Dissertação (Mestrado em Sociologia) Faculdade de Filosofia, Letras e Ciências Humanas, Universidade de São Paulo, 2010.

BRASIL. Lei 6.404 de 15 de dezembro de 1976. Dispõe sobre as Sociedade por Ações.

BRIGHAM, Eugene F.; Ehrhardt, Michael C. Financial Management: Theory \& Practice:

Cengage Learning, 2012.

COSTA SANTOS, Marcos Igor; SILVA, Manuel Soares. Teoria de precificação por arbitragem: um estudo empírico no setor bancário brasileirodoi: 10.4025/enfoque. v28i1. 8080. Enfoque:

Reflexão Contábil, v. 28, n. 1, p. 70-82, 2009.

COSTA, O. L. V.; ASSUNÇÃO, H. G. V. Análise de risco e retorno em investimentos financeiros. Barueri: Manole, 2005.

EID JÚNIOR, William. Risco nas aplicações financeiras e os fundos de investimento. 2017.
GITMAN, Lawrence J. Principles

of Managerial Finance - 12. Ed. - São Paulo:

Pearson Prentice Hall, 2010.

GRÜN, Roberto. A crise financeira, a guerra cultural e as transformações do espaço econômico Brasileiro em 2009. Dados, v. 53, n. 2, p. 255297, 2010.

INSTITUCIONAL GRUPO SANTANDER. O Santander. Disponível em: <https://www.santander.com.br/br/o-santander> Acesso em: 22 de Janeiro 2018.

INSTITUCIONAL BM\&FBOVESPA. Quem somos? Disponível em: < http://www.bmfbovespa.com.br/pt_br/instituciona 1/sobre-a-bm-fbovespa/quem-somos/>Acesso em: 22 de Janeiro de 2018.

INSTITUCIONAL ITAÚ. Quem somos?

Disponível em:

<https://www.itau.com.br/sobre/quem-somos/> Acesso em: 22 de Janeiro de 2018.

INSTITUCIONAL CIELO. Conheça a Cielo. Disponível em:

<https://www.cielo.com.br/conheca-a-cielo/

> Acesso em: 22 de Janeiro de 2018.

INSTITUCIONAL BRADESCO. Sobre o Bradesco. Disponível em: $<$ https://banco.bradesco/html/classic/sobre/index. shtm > Acesso em: 22 de Janeiro de 2018.

INSTITUCIONAL BANCO DO BRASIL. Sobre Nós. Disponível em: $<$ http://www.bb.com.br/pbb/pagina-inicial/sobrenos\#/> Acesso em: 22 de Janeiro de 2018.

LEITE, Helio de Paula. Introdução á administração financeira. 2. Ed. São Paulo: Atlas, 1994.

LENCIONE, M. A. Modelos de precificação. 2005.

LUCENA, Pierre; DA MOTTA, Luiz Felipe Jacques. Aplicação de um novo modelo de análise de risco na Bovespa: o D-CAPM. Revista Eletrônica de Administração, v. 10, n. 5, 2004.

O MERCADO DE VALORES MOBILIÁRIOS BRASILEIRO / COMISSÃO DE VALORES 
MOBILIÁRIOS. 3. ed. Rio de Janeiro: Comissão de Valores Mobiliários, 2014. 376p. : il.

PAULA, Anderson; TRICHES, Divanildo. O mercado acionário e o desempenho dos ativos financeiros no Brasil com emprego da análise técnica. Perspectiva Econômica, v. 6, n. 1, p. 37-62, 2010.

ROSS, Stephen. "The Arbitrage Theory oF Capital Asset Pricing". Journal Economic Theory, December 1976, V. 13, p. 341 - 360.

ROSS, Stephen A.; Westerfield, Randolph W.;Jaffe, Jeffrey F; Administração financeira tradução Antonio Zorrato Sanvicente. - 2. Ed. 9. Reimpr. - São Paulo: Atlas , 2009.

ROSS, Stephen A. et al. Administração

financeira. AMGH Editora, 2015.

SANTOS, JOSÉ ODÁLIO; FONTES, RICARDO JOSÉ SILVA. Análise da Relação entre o Coeficiente Beta, o Índice de Alavancagem D/E e a Taxa de Retorno de Ações Ordinária de uma Amostra de Empresas listadas no Ibovespa. Contabilidade Vista \& Revista, v. 22, n. 4, p. 173-197, 2013.

\section{SISTEMA DE ANALISE DE INVESTIMENTO} ECONOMATICA. Bovespa atinge o maior volume de movimentação financeira em 2016 Setor bancário lidera - PETR4 é a mais líquida. Disponível em: <https://economatica.com/estudos/data/20161219 a.pdf> . Acesso em: 26 de Junho de2017.
SISTEMA DE ANALISE DE INVESTIMENTO ECONOMATICA. Bovespa em março tem o segundo melhor mês em volume negociado da história. O desempenho do Ibovespa em março é o melhor desde outubro de 2002 e o sexto melhor desde janeiro de 1999. Disponível em: <https://economatica.com/estudos/data/20160408 a.pdf> . Acesso em: 26 de Junho de2017.

TERRA, Paulo Renato Soares. Inflação e retorno do mercado acionário em países desenvolvidos e emergentes. Revista de Administração Contemporânea, v. 10, n. 3, p. 133-158, 2006.

\section{Bruno Uriel Silva Santos}

Graduado em Ciências Contábeis - UFGD

Rafael Martins Noriller

Doutorando em Ciências Contábeis UnB

Docente FACE-UFGD

\section{Antonio Carlos Vaz Lopes \\ Doutor em Administração UNINOVE \\ Docente FACE-UFGD}

\author{
Manfredo Rode \\ Mestre em Agronegócio - UFGD
}

Docente FACE-UFGD 